\title{
Synthesis, Characterization and Chemical Stability of Silicon Dichalcogenides, $\mathrm{Si}\left(\mathrm{Se}_{\mathrm{x}} \mathrm{S}_{1-\mathrm{x}}\right)_{2}$
}

Chen Chen ${ }^{1}$, Xiaotian Zhang ${ }^{1}$, Lakshmi Krishna ${ }^{2}$, Chito Kendrick ${ }^{3}$, Shun-Li Shang ${ }^{1}$, Eric Toberer ${ }^{2,4}$, Zi-Kui Liu ${ }^{1}$, Adele Tamboli ${ }^{4}$, and Joan M. Redwing ${ }^{1 *}$

${ }^{1}$ Department of Materials Science and Engineering, Materials Research Institute, Pennsylvania State University, University Park, PA 16802, United States.

${ }^{2}$ Department of Physics, Colorado School of Mines, CO 80401, United States.

${ }^{3}$ Department of Electrical and Computer Engineering, Michigan Technological University, MI 49931, United States.

${ }^{4}$ National Center for Photovoltaics, National Renewable Energy Laboratory, Golden, CO 80404, United States.

\begin{abstract}
Silicon dichalcogenides have an intriguing crystal structure consisting of long tetrahedral chains held together by van der Waals forces but the electronic and optical properties have been less explored. In the present work, bulk $\mathrm{SiSe}_{2}, \mathrm{SiS}_{2}$, and $\mathrm{Si}\left(\mathrm{Se}_{\mathrm{x}} \mathrm{S}_{1-\mathrm{x}}\right)_{2}$ were synthesized by the congruent melt growth method and characterized by Raman spectroscopy, X-ray Diffraction and UV/visible/IR transmission measurements supported by first-principles calculations. First-principles calculations reveal a nearly linear decrease of band gap energy in $\mathrm{Si}\left(\mathrm{Se}_{\mathrm{x}} \mathrm{S}_{1-\mathrm{x}}\right)_{2}$ with increasing $\mathrm{Se}$ content, i.e., from $\mathrm{SiS}_{2}$ to $\mathrm{SiSe}_{2}$ which corresponds with a blue-shift in the transmission spectra from bulk $\mathrm{SiSe}_{2}$ to $\mathrm{Si}\left(\mathrm{Se}_{0.6} \mathrm{~S}_{0.4}\right)_{2}$, and to $\mathrm{SiS}_{2}$. Air stability tests demonstrate the formation of toxic $\mathrm{H}_{2} \mathrm{Se}_{2} \mathrm{H}_{2} \mathrm{~S}$ gas from sample oxidation at room temperature upon exposure to ambient air, and great care should be paid when handling these materials.
\end{abstract}

\section{KEYWORDS}

A1. Characterization, A1, Computer simulation, A2. Growth from melt, B1. Sulfides, B3. Solar cells, 


\section{INTRODUCTION}

Silicon is a ubiquitous material in modern technology, forming the backbone of integrated circuits and photovoltaic devices. This is due partially to its ability to form large high purity crystals and wafers as well as a variety of Si-based compounds such as $\mathrm{SiO}_{2}$ and $\mathrm{Si}_{3} \mathrm{~N}_{4}$ which play an integral role in device processing and performance. Recently, there has been increasing interest in layered semiconductors such as the transition metal dichalcogenides (TMDs, for example $\mathrm{MoS}_{2}$ and $\mathrm{WSe}_{2}$ ) due to the unique properties of monolayer and a few-layered films [1][2]. The TMDs are comprised of twodimensional sheets of covalently-bonded atoms which are held together by van der Waals forces. The silicon-based dichalcogenides e.g. bulk $\mathrm{SiSe}_{2}$ and $\mathrm{SiS}_{2}$, in contrast, consist of long edge-sharing chains of $\mathrm{SiSe}_{4}$ and $\mathrm{SiS}_{4}$ tetrahedrons, which are held together via van der Waals forces [3][4] (see Figure 1) but their syntheses and properties are relatively less explored. The ternary alloy system $\mathrm{Si}\left(\mathrm{Se}_{\mathrm{x}} \mathrm{S}_{1-\mathrm{x}}\right)_{2}$ is believed to possess an indirect band gap ranging from approximately $1.73 \pm 0.05 \mathrm{eV}$ (experimental value [5]) for $\mathrm{SiSe}_{2}$ up to 2.44 $\mathrm{eV}$ (prediction [6]) or $5.0 \mathrm{eV}$ (prediction [7]) for $\mathrm{SiS}_{2}$ (note that the experimental band gap is absent in the literature for $\mathrm{SiS}_{2}$ ). The range of band gaps is very interesting for a variety of optoelectronic devices. For example, the lower end of the band gap range is ideal for the top absorber cell of a tandem photovoltaic device based on a monocrystalline silicon bottom cell. A two-junction tandem cell of this type has a theoretical efficiency up to $45 \%$ (neglecting Auger losses) [8].

Initial studies of $\mathrm{Si}\left(\mathrm{Se}_{\mathrm{x}} \mathrm{S}_{1-\mathrm{x}}\right)_{2}$ were carried out in the 1980s with the focus being on the synthesis and structural characterization of the binary compounds $\mathrm{SiSe}_{2}$ and $\mathrm{SiS}_{2}$. Single crystal $\mathrm{SiSe}_{2}$ was prepared by melt growth using $\mathrm{Si}$ and Se powders in a sealed quartz ampoule [9]. The glassy form of $\mathrm{Si}_{x} \mathrm{Se}_{1-\mathrm{x}}$ was synthesized by quenching the ampoule with the molten alloy in water [10]. Bletskan[11] reviewed the melt and gas phase methods to fabricate single crystals of $\mathrm{SiSe}_{2}, \mathrm{SiS}_{2}$ and the related $\mathrm{A}^{\mathrm{IV}} \mathrm{B}^{\mathrm{VI}}$ materials. In 1985, Tenhoveret al. [12] synthesized a series of the glassy $\operatorname{Si}\left(\mathrm{S}_{\mathrm{X}} \mathrm{Se}_{1-\mathrm{x}}\right)_{2}$ alloys and studied their vibrational properties using Raman spectroscopy. It should be mentioned that discrepancies exist in the literature concerning the color of as-synthesized $\mathrm{SiSe}_{2}$. Hauschild et al.[5] reported single crystalline $\mathrm{SiSe}_{2}$ in the form of dark red rods of $1 \mathrm{~cm}$ 
to $1.5 \mathrm{~cm}$ in length, while Peter et al. [9] described needle-shaped and colorless single crystal $\mathrm{SiSe}_{2}$. Griffiths et al. [13], however, reported fibrous white crystals of $\mathrm{SiSe}_{2}$. Additionally, optical transmission measurement by Hauschild et al. [5], indicated that the single crystal $\mathrm{SiSe}_{2}$ is an indirect band gap semiconductor with a band gap energy $\leq 1.73$ $\pm 0.05 \mathrm{eV}$. Furthermore, $\mathrm{SiSe}_{2}$ (also true for $\mathrm{SiS}_{2}$ ) was found to react readily with $\mathrm{H}_{2} \mathrm{O}$ upon exposure to the moist air, resulting in the formation of toxic $\mathrm{H}_{2} \mathrm{Se}$ gas [13], since the chemical reaction (eqn. 1) possesses a negative reaction enthalpy $(-47 \mathrm{~kJ} /$ mole-atom at room temperature based on SGTE data [14] and [15]).

$$
\mathrm{SiSe}_{2}(\mathrm{~s})+\mathrm{H}_{2} \mathrm{O}(\mathrm{g}) \rightarrow \mathrm{SiO}_{2}(\mathrm{~s})+\mathrm{H}_{2} \mathrm{Se}(\mathrm{g})
$$

In summary, limited and even conflicting information exists regarding the optical properties such as the band gap energy of $\mathrm{SiS}_{2}$ and the color and chemical stability of $\mathrm{SiSe}_{2}, \mathrm{SiS}_{2}$, and $\mathrm{Si}\left(\mathrm{Se}_{\mathrm{x}} \mathrm{S}_{1-\mathrm{x}}\right)_{2}$.

The present work was aimed at synthesizing a series of bulk $\mathrm{SiSe}_{2}, \mathrm{SiS}_{2}$, and $\mathrm{Si}\left(\mathrm{Se}_{\mathrm{x}} \mathrm{S}_{1-\mathrm{x}}\right)_{2}$ crystals via the congruent melt growth by varying the stoichiometric ratios of the starting materials. Their structural and optical properties were investigated using Raman spectroscopy, X-ray Diffraction (XRD) and Ultraviolet-Visible-Infrared (UVVIS-IR) transmission spectroscopy. First-principles calculations were used to predict Raman modes and bandgap energies for $\mathrm{SiSe}_{2}$ and $\mathrm{SiS}_{2}$ for comparison to the experimental results.

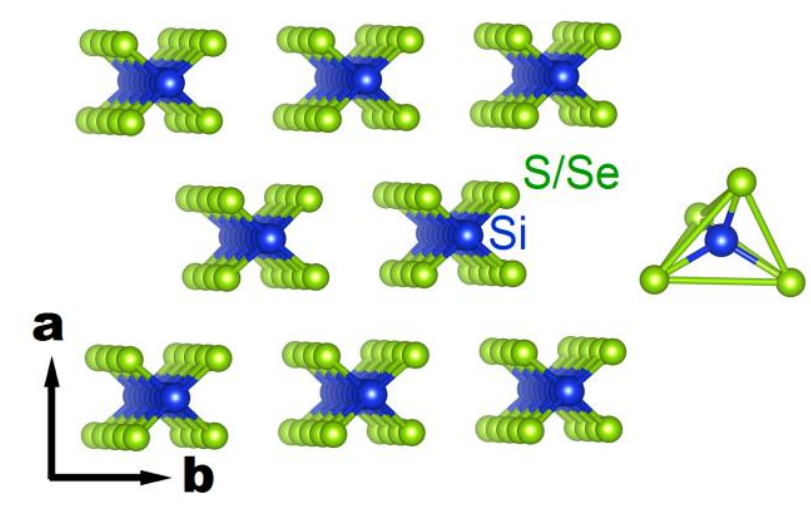

Figure 1: Crystal structure of $\mathrm{SiSe}_{2}$ or $\mathrm{SiS}_{2}$ consisting of needle-like chains of edgesharing SiSe ${ }_{4}$ and SiS $\mathrm{St}_{4}$ trahedra bonded via van der Waals forces along the a-axis and b-axis directions. 


\section{EXPERIMENTAL AND SIMULATION DETAILS}

$\mathrm{SiSe}_{2}, \mathrm{SiS}_{2}$, and $\mathrm{Si}\left(\mathrm{Se}_{\mathrm{x}} \mathrm{S}_{1-\mathrm{x}}\right)_{2}$ crystals were synthesized via congruent melting by varying the stoichiometric ratios of the starting materials. The source materials were powders including 350 mesh 99.999\% silicon, 200 mesh 99.999\% selenium, and 200 mesh 99.999\% sulfur. Stoichiometric amounts of these Si, Se and S powders were weighed and mixed. The quartz tubes used herein were $7 \mathrm{~mm}$ inner diameter, $9 \mathrm{~mm}$ outer diameter, and $30 \mathrm{~cm}$ in length before sealing. Before the sources were introduced into the quartz tubes, the tubes were sealed at one end and rinsed in acetone, 2-propanal, deionized water and were baked to dry.

For melt growth, 1.5 grams of powder was introduced into a quartz tube. A piece of quartz wool was put in the neck of the ampoule in order to prevent the powder from being pumped out during sealing. Then, the tube was evacuated to $10^{-2}$ to $10^{-3}$ Torr and sealed by flame heating. The sealed ampoules were then transferred into a tube furnace (LECO ${ }^{\circledR}$ TF-1 Tube Furnace) and annealed at $1100{ }^{\circ} \mathrm{C}$ for 8 hours. A small temperature gradient across the ampoule results in vapor transport of the Se and $\mathrm{S}$ species from the hotter to the cooler end of the ampoule during growth, which changes the stoichiometry of the original sources. To reduce this effect, the source end of the ampoule was always placed in the cooler end of the heat zone. Step-controlled cooling was used for all samples to further improve the compositional uniformity of the samples. The temperature was decreased in $50{ }^{\circ} \mathrm{C}$ increments and held for 3 minutes after each step from $1100{ }^{\circ} \mathrm{C}$ to $500{ }^{\circ} \mathrm{C}$. The sample was then allowed to cool naturally to room temperature.

After the melt growth, the $\mathrm{SiSe}_{2}, \mathrm{SiS}_{2}$, and $\mathrm{Si}\left(\mathrm{Se}_{\mathrm{x}} \mathrm{S}_{1-\mathrm{x}}\right)_{2}$ samples were characterized by Raman spectroscopy and UV-VIS-IR spectroscopy while the samples were still in the sealed ampoules. A WITec ${ }^{\circledR}$ Raman spectroscope with an incident laser beam of $488 \mathrm{~nm}$ was used for all sample characterization, and a LAMBDA ${ }^{\mathrm{TM}} 950$ UV-VIS-IR spectrophotometer (Perkin Elmer) with a $150 \mathrm{~mm}$ integrating sphere was used to measure the overall transmittance of the samples from 300 to $1100 \mathrm{~nm}$. The transmission spectrum of the quartz ampoule was subtracted from the data. The chemical stability of the samples was tested by cracking the quartz ampoules and exposing the materials to ambient air inside a ventilated hood. A calibrated gas detector (Honeywell Analytics ${ }^{\circledR}$ 
SPM Single Point Monitor) was used to measure the concentration of $\mathrm{H}_{2} \mathrm{Se}$ and $\mathrm{H}_{2} \mathrm{~S}$ produced by the samples as a function of distance from the open end of the quartz tube. The detectable gas range for $\mathrm{H}_{2} \mathrm{Se}$ and $\mathrm{H}_{2} \mathrm{~S}$ was $20 \sim 150 \mathrm{ppb}$.

First-principle calculations were used to examine the phonon frequencies at $\Gamma$ point and band gaps in $\operatorname{Si}\left(\mathrm{Se}_{\mathrm{x}} \mathrm{S}_{1-\mathrm{x}}\right)_{2}$ with space group Ibam (No. 72) [9]. All first-principles calculations in the present work were carried out using the Vienna Ab-initio Simulation Package (VASP 5.3.5) [16][17], together with the ion-electron interaction described by the projector augmented wave method (PAW) [18]. The selected exchange-correlation (X-C) functionals were mainly based on our previous tests on $\alpha$-sulfur and sulfurcontaining material [19], i.e., the van der Waals correction (the D3 method [20] employed herein) together with the generalized gradient approximation (GGA-PBE [21]) and the improved GGA of PBEsol [22]. In addition, ancillary calculations were also performed using the X-C functional of the local density approximation (LDA) [23]. To gain accurate band gaps, we employed the hybrid X-C functional of Heyd-ScuseriaErnzerhof (HSE)[24][25] with a range of separation parameter $\mu$. For the example of the GGA-PBE, the $\mu$ value switches the X-C functional from PBE0 $(\mu=0), \operatorname{HSE06}(\mu=0.2)$, HSE03 ( $\mu=0.3$ ), to $\operatorname{PBE}(\mu=$ infinitely large). Concerning the valence configuration, six electrons $\left(3 s^{2} 3 p^{4}\right)$ were treated as valence electrons for sulfur (S), six $\left(4 s^{2} 4 p^{4}\right)$ for Se, and four $\left(3 s^{2} 3 p^{2}\right)$ for Si. During VASP calculations for the 12-atom $\mathrm{Si}(\mathrm{S}, \mathrm{Se})_{2}$, in general we used a plane wave energy cutoff of $360 \mathrm{eV}$ and a $k$-point mesh of $7 \times 11 \times 11$ (or $4 \times 7 \times 7$ for the time-consuming HSE calculations). The reciprocal-space energy integration was performed using the Gauss smearing method for structural relaxations and phonon calculations. Final calculations of total energies and band gaps were performed by the tetrahedron method incorporating a Blöchl correction [26]. The self-consistency of total energy was converged to better than $10^{-6} \mathrm{eV} /$ atom.

Phonon calculations of $\mathrm{SiS}_{2}$ and $\mathrm{SiSe}_{2}$ were performed using the direct method in terms of a 48 -atom $1 \times 2 \times 2$ supercell. Force constants were calculated directly using the VASP code with the $k$-points mesh of $5 \times 5 \times 5$. Phonon properties were predicted using the mixed-space approach [27] as implemented in the YPHON code [28]. Note that the mixed-space approach was recently developed with force constants computed from the 
real space and the long-range dipole-dipole interactions computed from the reciprocal space, and it works well for both polar and nonpolar materials [27]. In the present work, the long-range dipole-dipole interactions including properties of the Born effective charge tensor and dielectric tensor, which result in the longitudinal optical-transverse optical (LO-TO) splitting, were calculated from the linear response method.

\section{RESULTS \& DISCUSSION}

Prior to annealing, the source powder mixtures are black in the quartz ampoules as shown in Fig. 2(a). After annealing at $1100{ }^{\circ} \mathrm{C}$ for 8 hours and step-cooling, the sample color changes from white for $\mathrm{SiS}_{2}$, to orange for $\mathrm{Si}\left(\mathrm{Se}_{\mathrm{x}} \mathrm{S}_{1-\mathrm{x}}\right)_{2}$, and to dark red for $\mathrm{SiSe}_{2}$, as shown in Fig. 2(b-f), demonstrating a clear color gradient with increasing Se content. The sample color varies from some of the reports in the literature. For example, Peter et al. [9] reported a colorless single crystal $\mathrm{SiS}_{2}$ prepared in a sealed quartz-glass tube at $1420 \mathrm{~K}$ by reacting $\mathrm{Al}_{2} \mathrm{~S}_{3}$ and $\mathrm{SiO}_{2}$ in a dry $\mathrm{N}_{2}$ stream. In the case of crystal $\mathrm{SiSe}_{2}$, it was reported to be white and needle-like [29], dark red rods [5], needle-shaped and colorless [9], and reddish brown [30]. The reason for the reported color variations is unclear; however, the dark red/reddish brown color of $\mathrm{SiSe}_{2}$ obtained in this study is consistent with a bandgap energy in the range of 1.6-1.8 eV.
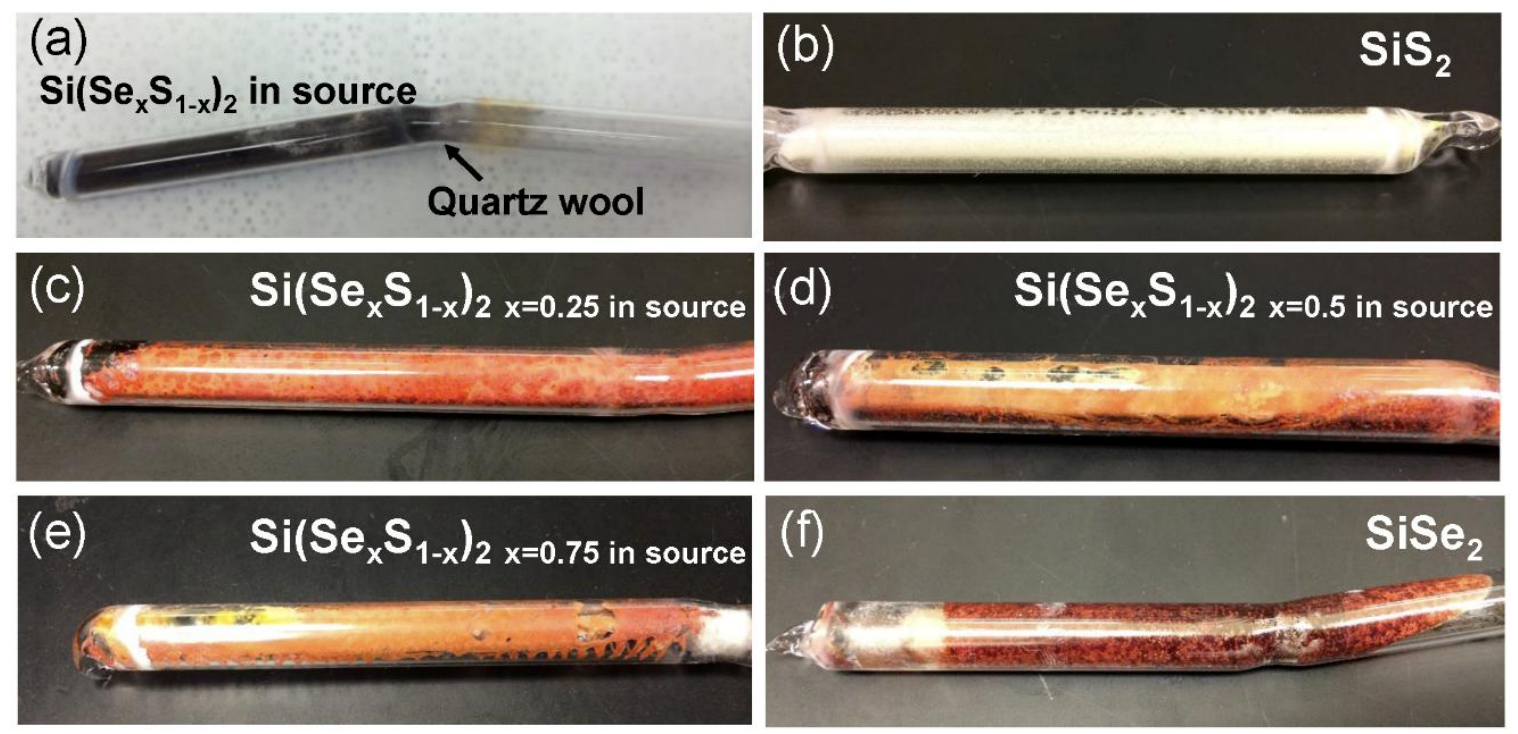
Figure 2: Photos of samples in sealed quartz ampoule before (a) and after annealing for starting stoichiometries of: (b) $\mathrm{SiS}_{2},(c)-(e): \operatorname{Si}\left(\mathrm{Se}_{x} S_{1-x}\right)_{2}$, with $x=0.25,0.5,0.75$ in source, and (f) $\mathrm{SiSe}_{2}$.

Raman spectroscopy measurements were used for phase identification of $\mathrm{SiSe}_{2}$, $\mathrm{SiS}_{2}$ and $\mathrm{Si}\left(\mathrm{Se}_{\mathrm{x}} \mathrm{S}_{1-\mathrm{x}}\right)_{2}$ alloys. A complete list of the 18 phonon modes for $\mathrm{SiS}_{2}$ and $\mathrm{SiSe}_{2}$ (space group Ibam with 6 atoms in the primitive cell) was given by Griffiths et al. [13],

$\Gamma=2 A_{g}^{(R)}+3 B_{1 g}^{(R)}+2 B_{2 g}^{(R)}+2 B_{3 g}^{(R)}+A_{u}+2 B_{1 u}^{(R)}+3 B_{2 u}^{(R)}+3 B_{3 u}^{(R R)}$

where the superscripts $R$ and $I R$ indicate the Raman and infrared active modes. $A_{u}$ is an inactive mode and the three acoustic modes are $B_{1 u}, B_{2 u}$, and $B_{3 u}$. Prior studies of $\mathrm{SiSe}_{2}$ and $\mathrm{SiS}_{2}$ attributed these modes to the crystalline forms of $\mathrm{SiSe}_{2}$ and $\mathrm{SiS}_{2}$, respectively [13][3], as shown in Table 1 with the calculated and experimental phonon frequencies at the $\Gamma$ point of $\mathrm{SiS}_{2}$ and $\mathrm{SiSe}_{2}[3,29,31,7,4,13]$.

Table 1. Calculated and experimental phonon frequencies at $\Gamma$ point of $\mathrm{SiS}_{2}$ and $\mathrm{SiSe}_{2}$, where $R$ and IR indicate the Raman and infrared active modes, respectively.

\begin{tabular}{|c|c|c|c|c|c|c|c|c|c|c|c|c|c|c|c|c|}
\hline $\begin{array}{l}\mathrm{SiX} \\
2\end{array}$ & Method & $A_{g}^{(R)}$ & $A_{g}^{(R)}$ & $B_{1 g}^{(R)}$ & $B_{1 g}^{(R)}$ & $B_{1 g}^{(R)}$ & $B_{2 g}^{(R)}$ & $B_{2 g}^{(R)}$ & $B_{3 g}^{(R)}$ & $B_{3 g}^{(R)}$ & $A_{u}$ & $B_{1 u}^{(I R)}$ & $B_{2 u}^{(I R)}$ & $B_{2 u}^{(I R)}$ & $B_{3 u}^{(I R)}$ & $B_{3 u}^{(I R)}$ \\
\hline \multirow[t]{6}{*}{$\mathrm{SiS}_{2}$} & PBEsol+D3 $^{\mathrm{a}}$ & 421 & 143 & 613 & 333 & 84 & 435 & 165 & 423 & 176 & 359 & $\begin{array}{l}459 \\
(575)\end{array}$ & $\begin{array}{l}575 \\
(594) \\
\end{array}$ & $\begin{array}{l}179 \\
(181)\end{array}$ & $\begin{array}{l}563 \\
(584) \\
\end{array}$ & $\begin{array}{l}191 \\
(192) \\
\end{array}$ \\
\hline & $\mathrm{PBE}+\mathrm{D} 3^{\mathrm{a}}$ & 419 & 139 & 607 & 338 & 74 & 422 & 172 & 419 & 179 & 359 & $\begin{array}{l}452 \\
(570)\end{array}$ & $\begin{array}{l}567 \\
(584) \\
\end{array}$ & $\begin{array}{l}179 \\
(180) \\
\end{array}$ & $\begin{array}{l}564 \\
(582) \\
\end{array}$ & $\begin{array}{l}185 \\
(185) \\
\end{array}$ \\
\hline & Expt. ${ }^{a}$ & 437 & 143 & 631 & 356 & & & 181 & & & & & & & & \\
\hline & Expt. $^{b}$ & 430 & 138 & 625 & 351 & & & 181 & & 175 & & 590 & 402 & & 487 & \\
\hline & Expt. $^{\mathrm{c}}$ & & & & & & & & & & & 475 & & 188 & 475 & 188 \\
\hline & Calc. $^{d}$ & 445 & 143 & 640 & 363 & 64 & 450 & 181 & 443 & 187 & & $\begin{array}{l}485 \\
(610) \\
\end{array}$ & $\begin{array}{l}608 \\
(624) \\
\end{array}$ & $\begin{array}{l}191 \\
(192) \\
\end{array}$ & $\begin{array}{l}596 \\
(624) \\
\end{array}$ & $\begin{array}{l}191 \\
(192) \\
\end{array}$ \\
\hline \multirow[t]{9}{*}{$\begin{array}{l}\mathrm{SiS} \\
\mathrm{e}_{2} \\
\end{array}$} & PBEsol+D3 ${ }^{\mathrm{a}}$ & 236 & 86 & 494 & 190 & 56 & 333 & 113 & 351 & 105 & 200 & $\begin{array}{l}369 \\
(449) \\
\end{array}$ & $\begin{array}{l}432 \\
(444) \\
\end{array}$ & $\begin{array}{l}118 \\
(119) \\
\end{array}$ & $\begin{array}{l}455 \\
(467) \\
\end{array}$ & $\begin{array}{l}102 \\
(103) \\
\end{array}$ \\
\hline & $\mathrm{PBE}+\mathrm{D} 3^{\mathrm{a}}$ & 235 & 87 & 491 & 194 & 56 & 340 & 109 & 331 & 115 & 201 & $\begin{array}{l}363 \\
(447) \\
\end{array}$ & $\begin{array}{l}448 \\
(458) \\
\end{array}$ & $\begin{array}{l}104 \\
(104) \\
\end{array}$ & $\begin{array}{l}437 \\
(448) \\
\end{array}$ & $\begin{array}{l}114 \\
(114) \\
\end{array}$ \\
\hline & Expt. $^{a}$ & 244 & 82 & 514 & 204 & & 350 & 113 & 350 & 113 & & & & & & \\
\hline & Expt. $^{b}$ & 248 & 82 & 512 & 204 & & 355 & 122 & 345 & 114 & & 492 & 397 & & 468 & \\
\hline & Expt. $^{\mathrm{e}}$ & 242 & 68 & 515 & 216 & & 350 & 110 & 350 & 110 & & 490 & 390 & & 460 & \\
\hline & Expt. $^{\mathrm{e}}$ & 237 & 70 & 515 & 213 & & 357 & 125 & & 125 & & & 387 & & 470 & \\
\hline & Expt. $^{\mathrm{e}}$ & 236 & 70 & 521 & 202 & & 358 & 131 & & 131 & & & 380 & & 470 & \\
\hline & Expt. $^{f}$ & 242 & 81 & 516 & 218 & 48 & 367 & 113 & & 113 & & & 399 & & 472 & \\
\hline & Expt. $^{\mathrm{g}}$ & 245 & 83 & 515 & 205 & 47 & 357 & 114 & 347 & 120 & & & & & & \\
\hline
\end{tabular}

${ }^{a}$ The present work by first-principles calculations or experiments.

${ }^{\mathrm{b}}$ Measurements by Tenhoveret al. [3][29]

${ }^{\mathrm{c}}$ Measurements by Begemannet al. [31]

${ }^{\mathrm{d}}$ Predictions using PBE0 as implemented in GRYSTAL06 by Zwijnenburget al. [7] 
${ }^{\mathrm{e}}$ Measurements summarized by Arai et al. [4]

${ }^{\mathrm{f}}$ Measurements by Arai et al. [4]

${ }^{\mathrm{g}}$ Measurements by Griffiths et al. [13]

The Raman peaks in Fig. 3(a) correspond to crystalline $\mathrm{SiSe}_{2}$ [13]. The very intense and narrow peak at $244 \mathrm{~cm}^{-1}$ can be assigned to the $\left(v_{l}, A_{g}\right)$ symmetric stretching mode of $\mathrm{SiSe}_{4}$. The peak at $82 \mathrm{~cm}^{-1}$ is assigned to the $\left(v_{2}, A_{g}\right)$ mode which represents the bending coordinate with motional characteristics. The $350 \mathrm{~cm}^{-1}$ peak is the $\left(v_{8}, B_{3 g}\right)$ mode which represents the motions of silicon atoms transverse to the axes of the chains in an orthorhombic bridge structure. The $113 \mathrm{~cm}^{-1}$ peak is the $\left(v_{7}, B_{2 g}\right)$ mode and the $204 \mathrm{~cm}^{-1}$ peak is the $\left(v_{4}, B_{1 g}\right)$ mode which represents the scissor-like motion involving both bondstretching and angle-bending motions. It is worth noting that the $\left(v_{4}, B_{1 g}\right)$ mode is located at $204 \mathrm{~cm}^{-1}$ in crystalline $\mathrm{SiSe}_{2}$ but at $216 \mathrm{~cm}^{-1}$ in glassy $\mathrm{SiSe}_{2}$, as pointed out in the literature [29], which further provides evidence of the crystalline form of our synthesized $\mathrm{SiSe}_{2}$. Fig. 3(b) shows the Raman spectra of our $\mathrm{SiS}_{2}$ sample. Similar to $\mathrm{SiSe}_{2}$, the Raman spectra of $\mathrm{SiS}_{2}$ is also dominated by the normal modes of $\mathrm{Si}\left(\mathrm{S}_{1 / 2}\right)_{4}$ tetrahedra unit. According to Tenhoveret al. [3], the $B_{1 g}$ mode in glassy $\mathrm{SiS}_{2}$ is split into two peaks. Hence the present $\mathrm{SiS}_{2}$ sample can be verified to be crystalline $\mathrm{SiS}_{2}$. Figs. 3(c) and (d) show the first-principle phonon frequencies at $\Gamma$ point for $\mathrm{SiSe}_{2}$ and $\mathrm{SiS}_{2}$ in comparison with the present Raman results as well as the measurements in the literature $[3,4,7,13$, 29, 31], see details in Table 1. In Fig. 3(c) and (d), the PBEsol is an improved generalized gradient approximation (GGA) for solids and their surface [22]. D3 is one kind of van der Waals correction used in the present work [20]. R means Raman spectra, and IR means Infrared. A good agreement is found between the calculations and experiments. 

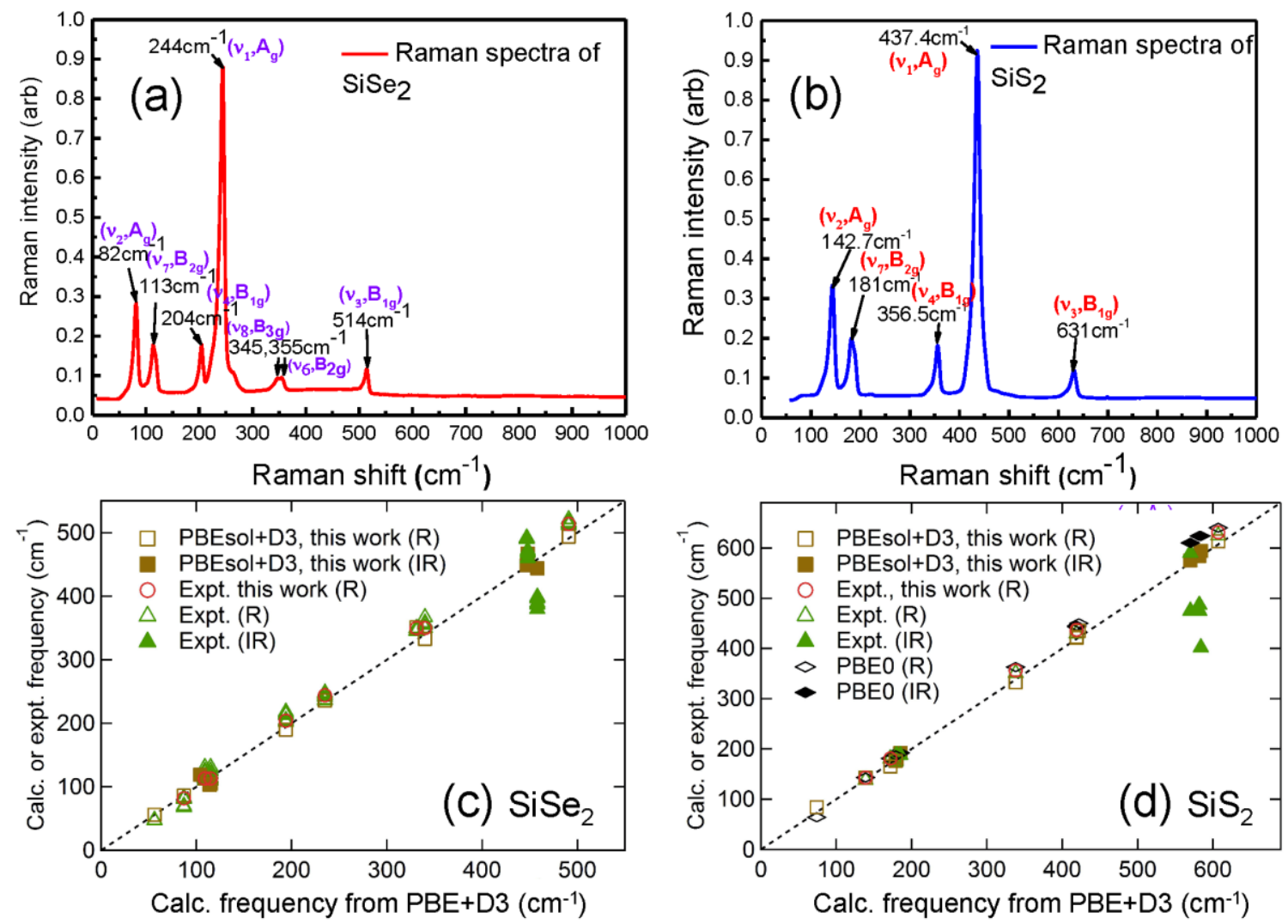

Figure 3: (a) Raman spectra of the synthesized $\mathrm{SiSe}_{2}$, (b) Raman spectra of the synthesized $\mathrm{SiS}_{2}$; and first-principle phonon frequencies at $\Gamma$ point in comparison with the present and other experimental results for (c) $\mathrm{SiSe}_{2}$ and (d) $\mathrm{SiS}_{2}$.

In the case of $\mathrm{Si}\left(\mathrm{Se}_{\mathrm{x}} \mathrm{S}_{1-\mathrm{x}}\right)_{2}$ as shown in Fig. 4(a), the Raman spectra exhibit a clear shift in $A_{g}$ mode with increasing Se content: $432 \mathrm{~cm}^{-1}$ peak in $\operatorname{Si}\left(\operatorname{Se}_{0.25} \mathrm{~S}_{0.75}\right)_{2}, 316 \mathrm{~cm}^{-1}$ in $\mathrm{Si}\left(\mathrm{Se}_{0.5} \mathrm{~S}_{0.5}\right)_{2}$, and $247 \mathrm{~cm}^{-1}$ in $\mathrm{Si}\left(\mathrm{Se}_{0.75} \mathrm{~S}_{0.25}\right)_{2}$. In order to determine the final composition in our $\mathrm{Si}\left(\mathrm{Se}_{\mathrm{x}} \mathrm{S}_{1-\mathrm{x}}\right)_{2}$ alloys, first-principle calculations were carried out in terms of the Raman peak of the $\left(v_{1}, A_{g}\right)$ mode as a function of the Se mole fraction, see Fig. 4(b). Based on calculated results of band gap and lattice parameter (volume) as a function of composition, the $\left(v_{l}, A_{g}\right)$ peak in Raman spectra should follow roughly a linear variation as a function of Se content. Given the position of the $\left(v_{l}, A_{g}\right)$ peak from Raman spectra, the mole fraction of Se in our samples can be estimated. From Fig. 4(b), it is worth noting that the synthesized ternary compounds are $\operatorname{Si}\left(\mathrm{Se}_{0.03} \mathrm{~S}_{0.97}\right)_{2}, \quad \operatorname{Si}\left(\mathrm{Se}_{0.6} \mathrm{~S}_{0.4}\right)_{2}$, and $\operatorname{Si}\left(\operatorname{Se}_{0.98} \mathrm{~S}_{0.02}\right)_{2}$. 

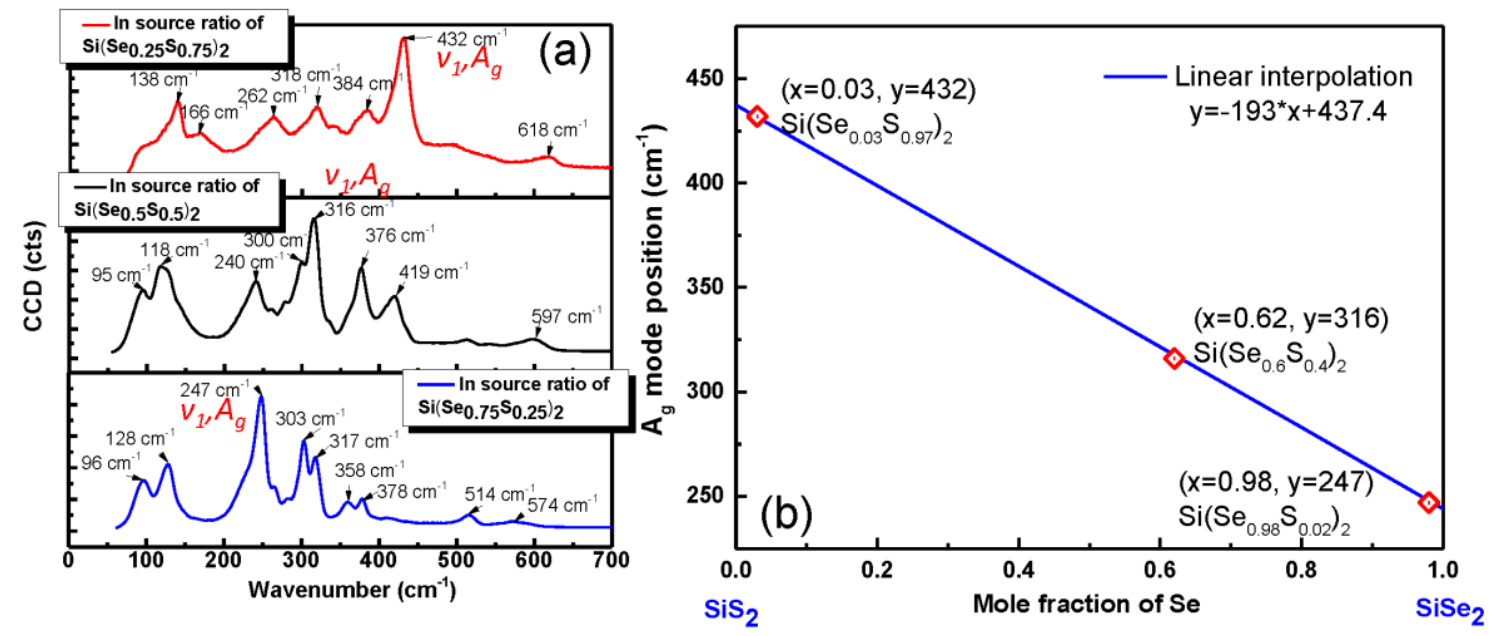

Figure 4: (a) Raman spectra of the synthesized $\operatorname{Si}\left(\operatorname{Se}_{x} S_{1-x}\right)_{2}$, and (b) the $\left(v_{1}, A_{g}\right)$ peak in Raman spectra as a function of Se content in the final Si(Se $\left.S_{1-x}\right)_{2}$ ternary compounds based on first-principle calculations.

To identify the crystal structure of $\mathrm{SiSe}_{2}$, a $\mathrm{SiSe}_{2}$ ampoule was opened in an inert glove box and the XRD data was collected using a Bruker D8 diffractometer located in the glove box, as shown in Fig. 5(a). The XRD system was setup in the conventional Bragg-Brentano geometry and employed a graphite monochromator. From the XRD data, $\mathrm{SiSe}_{2}$ was characterized as an orthorhombic structure and is consistent with the ICDD pattern no: 000250756. It was characterized from the sample shown in Fig. 5(b). The photo clearly shows the needle-like fibers in the synthesized $\mathrm{SiSe}_{2}$ ampoule. 

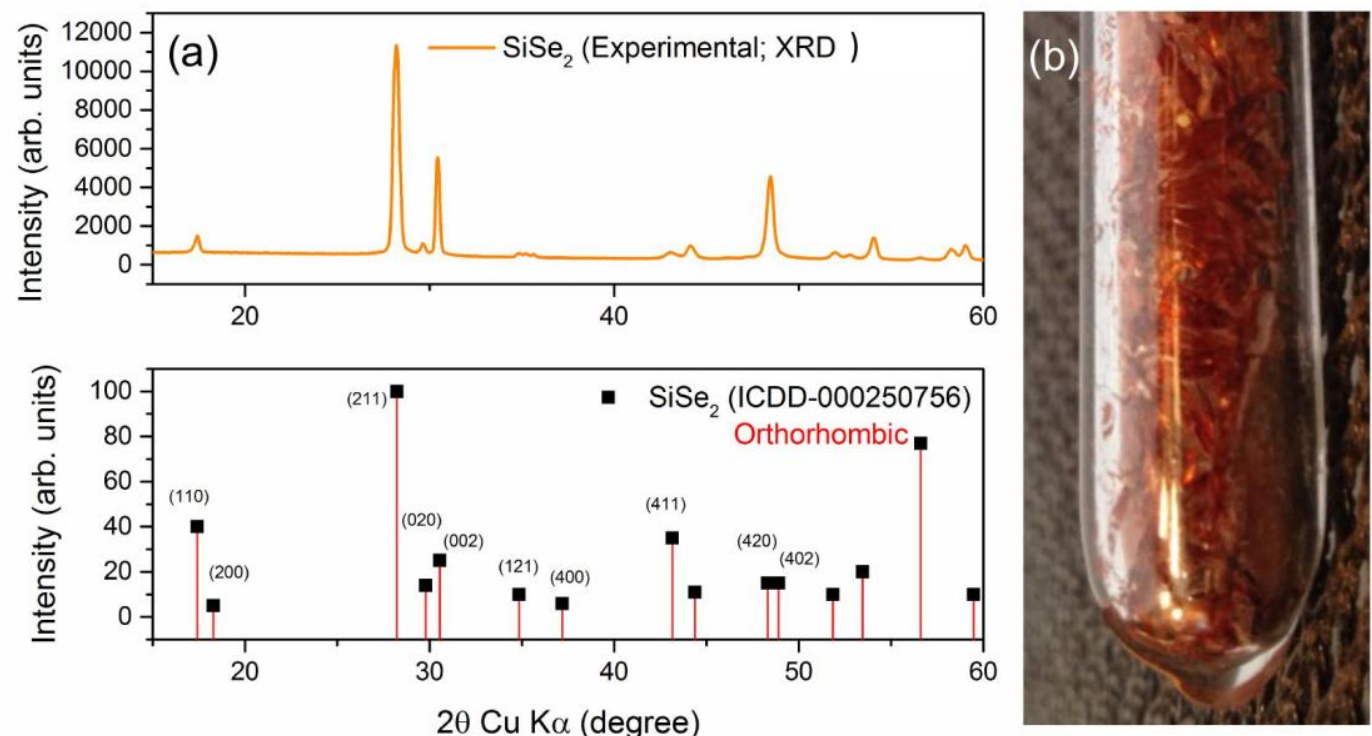

Figure 5: (a) XRD measurement on $\mathrm{SiSe}_{2}$ and ICDD pattern of the crystalline $\mathrm{SiSe}_{2},(b)$ Photo of synthesized SiSe $e_{2}$ sample which shows the needle-like fibers within the ampoule.

The band gaps of $\mathrm{SiSe}_{2}, \mathrm{SiS}_{2}$, and $\mathrm{Si}\left(\mathrm{Se}_{\mathrm{x}} \mathrm{S}_{1-\mathrm{x}}\right)_{2}$ are also predicted by first-principle calculations. Fig. 6(a) illustrates the variation of the band gap in $\operatorname{Si}\left(\operatorname{Se}_{\mathrm{x}} \mathrm{S}_{1-\mathrm{x}}\right)_{2}$ from the X$\mathrm{C}$ functionals of PBEsol+D3, PBE $+\mathrm{D} 3$, and $\mathrm{PBE}+\mathrm{D} 3+\Gamma(\mu=0.7)$. Note that the range separation parameter $\mu=0.7$ is selected based on a comparison of the calculated and measured band gaps for $\mathrm{SiSe}_{2}[5]$ and the selected PBE+D3 is based on a comparison of the calculated and measured lattice parameters of $\mathrm{SiS}_{2}$ and $\mathrm{SiSe}_{2}$ [9]. The more reliable $\mathrm{X}-\mathrm{C}$ functional is $\mathrm{PBE}+\mathrm{D} 3$, and the results from PBEsol+D3 are listed for reference. In general, Fig. 6(a) shows that the band gap of $\mathrm{Si}\left(\mathrm{Se}_{\mathrm{x}} \mathrm{S}_{1-\mathrm{x}}\right)_{2}$ decreases with increasing $\mathrm{Se}$ content, for example from $3.0 \mathrm{eV}(413 \mathrm{~nm})$ for $\mathrm{SiS}_{2}$ to $1.73 \mathrm{eV}(716 \mathrm{~nm})$ for $\mathrm{SiSe}_{2}$ based on the $\mathrm{X}-\mathrm{C}$ functional of $\mathrm{PBE}+\mathrm{D} 3+\mu$. Moreover, a slightly negative deviation is shown for the band gap of $\mathrm{Si}(\mathrm{S}, \mathrm{Se})_{2}$ as a function of Se content, and even the $\mathrm{X}-\mathrm{C}$ functional of $\mathrm{PBE}+\mathrm{D} 3$ can predict a reasonable band gap of $\mathrm{Si}\left(\mathrm{Se}_{\mathrm{x}} \mathrm{S}_{1-\mathrm{x}}\right)_{2}$. To compare to these predictions, UV-VIS-IR transmission spectroscopy was carried out on three samples of $\mathrm{SiSe}_{2}, \mathrm{Si}\left(\mathrm{Se}_{0.6} \mathrm{~S}_{0.4}\right)_{2}$, and $\mathrm{SiS}_{2}$, as shown in Fig. 6(b). Since the measurements were performed with the samples inside the sealed quartz ampoules, it was not possible to determine the sample thicknesses and therefore it was not possible to directly determine 
the optical band gaps of these samples. For the purposes of comparison, the transmission spectra for each sample were normalized to their maximum values, see Fig. 6(b). A blue shift was observed from $\mathrm{SiSe}_{2}$ to $\mathrm{Si}\left(\mathrm{Se}_{0.6} \mathrm{~S}_{0.4}\right)_{2}$ and to $\mathrm{SiS}_{2}$, which is consistent with the calculated results about the band gap variation for $\operatorname{Si}\left(\operatorname{Se}_{\mathrm{x}} \mathrm{S}_{1-\mathrm{x}}\right)_{2}$.
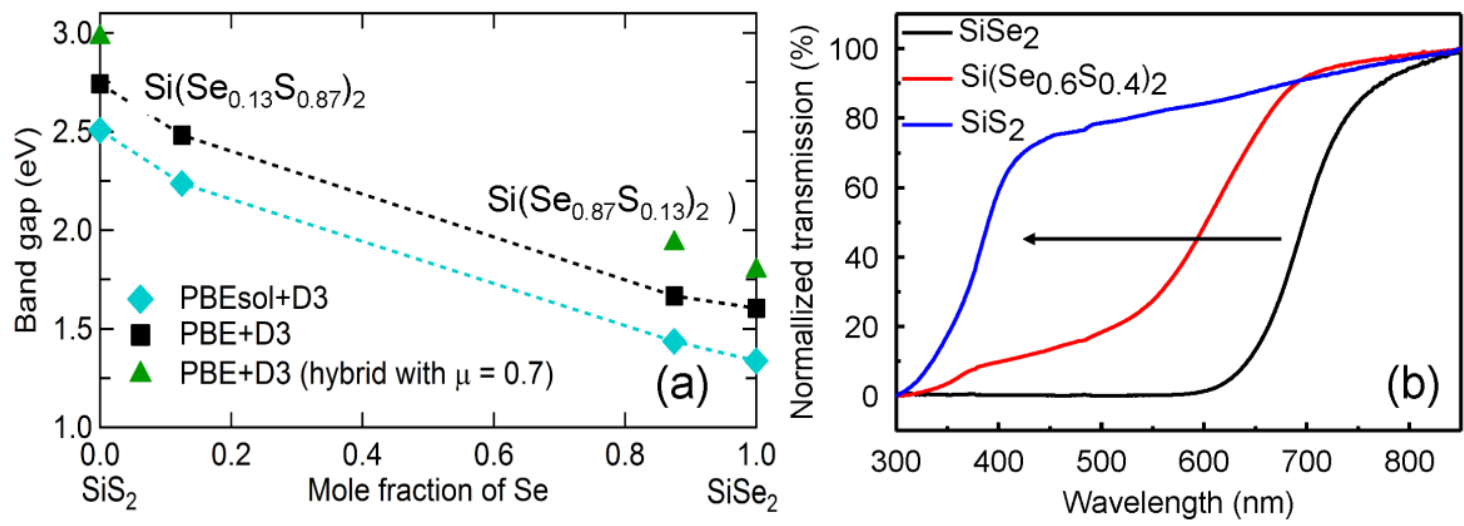

Figure 6: (a) Band gap of silicon dichalcogenides by first-principle predictions using three different $X$-C functionals. (b) UV/visible/IR transmission spectra for the synthesized samples $\mathrm{SiSe}_{2}, \mathrm{Si}\left(\mathrm{Se}_{0.6} \mathrm{~S}_{0.4}\right)_{2}$, and $\mathrm{SiS}_{2}$.

Silicon dichalcogenides will hydrolyze when exposed to moist air. For example, $\mathrm{SiSe}_{2}$ will form $\mathrm{SiO}_{2}$ and $\mathrm{H}_{2} \mathrm{Se}$ gas. $\mathrm{H}_{2} \mathrm{Se}$ is a colorless and flammable gas with a very offensive odor and is considered as one of the most toxic selenium compounds. The threshold limit value (TLV) of $\mathrm{H}_{2} \mathrm{Se}$, which represents the maximum recommended exposure for humans, is $50 \mathrm{ppb}$, and the median lethal concentration, i.e. the LC50 value, is $0.3 \mathrm{ppm}$ (guinea pig, 8 hours) and $5.9 \mathrm{ppm}$ (rat, 1 hour) (According to MSDS of $\mathrm{H}_{2} \mathrm{Se}$ ). Consequently, extreme care must be taken when handling these materials in air. To further assess the potential safety hazards, a gas detector was used to monitor the concentration of $\mathrm{H}_{2} \mathrm{Se}$ produced by the oxidation of $\mathrm{SiSe}_{2}$ in ambient air at room temperature after the quartz ampoules were broken open. The tests were carried out in the fume hood with a negative pressure. Almost immediately after exposure to air, the $\mathrm{H}_{2} \mathrm{Se}$ concentration above the sample reached the upper detection limit (150 ppb). These data indicate that $\mathrm{SiSe}_{2}$ reacts quickly when exposed to air and produces toxic $\mathrm{H}_{2} \mathrm{Se}$ gas. Note that similar results were also obtained with the $\mathrm{Si}_{2}$ sample exposed to air, emitting the 
$\mathrm{H}_{2} \mathrm{~S}$ gas due to a negative enthalpy for the reaction similar to Eq. (1), however, a quantitative measurement was not performed for this case.

\section{CONCLUSIONS}

In the present work, bulk $\mathrm{SiSe}_{2}, \mathrm{SiS}_{2}$, and $\mathrm{Si}\left(\mathrm{Se}_{\mathrm{x}} \mathrm{S}_{1-\mathrm{x}}\right)_{2}$ were synthesized via the congruent melt growth method. First-principle calculations were performed to predict the band gaps and to identify the Raman modes of $\operatorname{Si}\left(\operatorname{Se}_{\mathrm{x}} \mathrm{S}_{1-\mathrm{x}}\right)_{2}$. A good agreement was found between calculations and experiments. We show a nearly-linear decrease of band gap in $\mathrm{Si}\left(\mathrm{Se}_{\mathrm{x}} \mathrm{S}_{1-\mathrm{x}}\right)_{2}$ with increasing $\mathrm{Se}$ content, i.e., from about $3.0 \mathrm{eV}$ for $\mathrm{SiS}_{2}$ to about $1.7 \mathrm{eV}$ for $\mathrm{SiSe}_{2}$, and the predicted band gaps are consistent with a blue shift in the UV-VIS-IR transmission spectra. Air stability measurement points out that toxic $\mathrm{H}_{2} \mathrm{Se} / \mathrm{H}_{2} \mathrm{~S}$ gas is readily formed when $\mathrm{Si}\left(\mathrm{Se}_{\mathrm{x}} \mathrm{S}_{1-\mathrm{x}}\right)_{2}$ is exposed to moist air, and great care needs to be paid when handling this material. 


\section{ACKNOWLEDGEMENTS}

This work was supported by the fund from the Chinese Council of Scholar (No. 2013049101), the Research Corporation for Science Advancement, and the Department of Energy under NREL NPO (No. 424-36 3736). S. L. S. and Z. K. L. would like to thank the financial support from the U.S. National Science Foundation under Grant No. CHE-1230924. The authors acknowledge helpful discussions with Reuben Collins throughout the study. 


\section{REFERENCES}

[1] Q.H. Wang, K. Kalantar-Zadeh, A. Kis, J.N. Coleman, M.S. Strano, Electronics and optoelectronics of two-dimensional transition metal dichalcogenides., Nat. Nanotechnol. 7 (2012) 699-712. doi:10.1038/nnano.2012.193.

[2] S.M. Eichfeld, L. Hossain, Y. Lin, A.F. Piasecki, B. Kupp, a G. Birdwell, et al., Highly Scalable, Atomically Thin WSe2 Grown via Metal Organic Chemical Vapor Deposition, (2015) 2080-2087. doi:10.1021/nn5073286.

[3] M. Tenhover, M.A. Hazle, R.K. Grasselli, Atomic Structure of SiS2 and SiSe2 Glasses, Phys. Rev. Lett. 51 (1983) 404-406.

[4] M. Arai, D.L. Price, S. Susman, K.J. Volin, U. Walter, Network Dynamics of Chalcogenide glasses, II. Silicon diselenide, Phys. Rev. B. 37 (1988) 4240-4245.

[5] E. a. Hauschild, C.R. Kannewurf, Optical transmission in single crystal silicon diselenide, Solid State Commun. 6 (1968) viii. doi:10.1016/0038-1098(68)90216-0.

[6] D.I. Bletskan, V. V. Vakulchak, K.E. Glukhov, Electronic structure of low-pressure and high-pressure phases of silicon disulfide, Appl. Phys. A. 117 (2014) 14991514. doi:10.1007/s00339-014-8584-z.

[7] M.A. Zwijnenburg, R.G. Bell, F. Corà, Structure, bonding and physical properties of tetragonal and orthorhombic SiS2 from (hybrid) DFT calculations, J. Solid State Chem. 181 (2008) 2480-2487. doi:10.1016/j.jssc.2008.06.006.

[8] F. Meillaud, a. Shah, C. Droz, E. Vallat-Sauvain, C. Miazza, Efficiency limits for single-junction and tandem solar cells, Sol. Energy Mater. Sol. Cells. 90 (2006) 2952-2959. doi:10.1016/j.solmat.2006.06.002.

[9] J. Peters, B. Krebs, Silicon disulphide and silicon diselenide: a reinvestigation, ActaCrystallogr. Sect. B Struct. Crystallogr. Cryst. Chem. 38 (1982) 1270-1272. doi:10.1107/S0567740882005469.

[10] J.E. Griffiths, M. Malyj, G.P. Espinosa, J.P. Remeika, Nonstoichiometric Selenium Rich SixSe1-x Films, Solid State Commun. 53 (1985) 587-590. 
[11] D.I. Bletskan, Glass formation in binary and ternary chalcogenide systems, Chalcogenide Lett. 3 (2006) 81-119.

[12] M. Tenhover, J.H. Harris, M.A. Hazle, H. Scher, R.K. Grasselli, Isoelectronic Substitution In Si(Sx, Se1-x)2 Glasses, J. Non. Cryst. Solids. 69 (1985) 249-259.

[13] J.E. Griffiths, M. Malyj, G.P. Espinosa, J.P. Remeika, Crystalline SiSe2 and SixSe1$\mathrm{x}$ glasses: Syntheses, glass formation, structure, phase separation, and Raman spectra, Phys. Rev. B. 30 (1984) 6978-6990.

[14] Scientific Group Thermodata Europe (SGTE), Ed., Thermodynamic Properties of Inorganic Materials, Landolt-Bornstein, New Series, Group IV, Vol. 19, Springer, Berlin, 1999.

[15] M.S. Chandrasekharaiah, J.L. Margrave, Enthalpies of Formation of Solid Silicon Dichalcogenides, J. Phys. Chem. Ref. Data. 23 (1994) 499. doi:10.1063/1.555960.

[16] G. Kresse, Efficient iterative schemes for ab initio total-energy calculations using a plane-wave basis set, Phys. Rev. B. 54 (1996) 11169-11186. doi:10.1103/PhysRevB.54.11169.

[17] G. Kresse, J. Furthmüller, Efficiency of ab-initio total energy calculations for metals and semiconductors using a plane-wave basis set, Comput. Mater. Sci. 6 (1996) 15-50. doi:10.1016/0927-0256(96)00008-0.

[18] G. Kresse, Fromultrasoft pseudopotentials to the projector augmented-wave method, Phys. Rev. B. 59 (1999) 1758-1775. doi:10.1103/PhysRevB.59.1758.

[19] S. Shang, Y. Wang, P. Guan, W.Y. Wang, H. Fang, T. Anderson, et al., Insight into structural, elastic, phonon, and thermodynamic properties of $\alpha$-sulfur and energyrelated sulfides: a comprehensive first-principles study, J. Mater. Chem. A. 3 (2015) 8002-8014. doi:10.1039/C4TA07062C.

[20] S. Grimme, J. Antony, S. Ehrlich, H. Krieg, A consistent and accurate ab initio parametrization of density functional dispersion correction (DFT-D) for the 94 elements H-Pu., J. Chem. Phys. 132 (2010) 154104. doi:10.1063/1.3382344. 
[21] J.P. Perdew, K. Burke, M. Ernzerhof, Generalized Gradient Approximation Made Simple, Phys. Rev. Lett. 77 (1996) 3865-3868. doi:10.1103/PhysRevLett.77.3865.

[22] J. Perdew, A. Ruzsinszky, G. Csonka, O. Vydrov, G. Scuseria, L. Constantin, et al., Restoring the Density-Gradient Expansion for Exchange in Solids and Surfaces, Phys. Rev. Lett. 100 (2008) 136406. doi:10.1103/PhysRevLett.100.136406.

[23] J.P. Perdew, Self-interaction correction to density-functional approximations for many-electron systems, Phys. Rev. B. 23 (1981) 5048-5079. doi:10.1103/PhysRevB.23.5048.

[24] J. Heyd, G.E. Scuseria, M. Ernzerhof, Erratum: "Hybrid functionals based on a screened Coulomb potential" [J. Chem. Phys. 118, 8207 (2003)], J. Chem. Phys. 124 (2006) 219906. doi:10.1063/1.2204597.

[25] J. Heyd, G.E. Scuseria, M. Ernzerhof, Hybrid functionals based on a screened Coulomb potential, J. Chem. Phys. 118 (2003) 8207. doi:10.1063/1.1564060.

[26] P.E. Blöchl, O. Jepsen, O.K. Andersen, Improved tetrahedron method for Brillouinzone integrations, Phys. Rev. B. 49 (1994) 16223-16233. doi:10.1103/PhysRevB.49.16223.

[27] Y. Wang, J.J. Wang, W.Y. Wang, Z.G. Mei, S.L. Shang, L.Q. Chen, et al., A mixedspace approach to first-principles calculations of phonon frequencies for polar materials., J. Phys. Condens. Matter. 22 (2010) 202201. doi:10.1088/09538984/22/20/202201.

[28] Y. Wang, L.-Q. Chen, Z.-K. Liu, YPHON: A package for calculating phonons of polar materials, Comput. Phys. Commun. 185 (2014) 2950-2968. doi:10.1016/j.cpc.2014.06.023.

[29] M. Tenhover, R.S. Henderson, D. Lukco, M.A. Hazle, R.K. Grasselli, Vibrational studies of crystalline and glassy SiSe2, Solid State Commun. 51 (1984) 455-459. doi:10.1016/0038-1098(84)91012-3. 
[30] A. Pradel, V.Michel-Lledos, M. Ribes, Two New Polymorphs of SiSe2 : Structural Investigation by Raman and Si MAS NMR Spectroscopies and Relationship with the Structure of Vitreous SiSe2, Chem. Mater. 2 (1993) 377-380.

[31] B. Begemann, J. Dorschner, T. Henning, H. Mutschke, Optical Properties of Glassy SiS2 and the 21 Micron Feature, Astrophys. J. 464 (1996) L195-L199. doi:10.1086/310110. 
Table 1. Calculated and experimental phonon frequencies at $\Gamma$ point of $\mathrm{SiS}_{2}$ and $\mathrm{SiSe}_{2}$, where $R$ and IR indicate the Raman and infrared active modes, respectively.

\begin{tabular}{|c|c|c|c|c|c|c|c|c|c|c|c|c|c|c|c|c|}
\hline $\begin{array}{l}\mathrm{SiX} \\
2\end{array}$ & Method & $A_{g}^{(R)}$ & $A_{g}^{(R)}$ & $B_{1 g}^{(R)}$ & $B_{1 g}^{(R)}$ & $B_{1 g}^{(R)}$ & $B_{2 g}^{(R)}$ & $B_{2 g}^{(R)}$ & $B_{3 g}^{(R)}$ & $B_{3 g}^{(R)}$ & $A_{u}$ & $B_{1 u}^{(I R)}$ & $B_{2 u}^{(I R)}$ & $B_{2 u}^{(I R)}$ & $B_{3 u}^{(I R)}$ & $B_{3 u}^{(I R)}$ \\
\hline \multirow[t]{6}{*}{$\mathrm{SiS}_{2}$} & PBEsol+D3 $^{\mathrm{a}}$ & 421 & 143 & 613 & 333 & 84 & 435 & 165 & 423 & 176 & 359 & $\begin{array}{l}459 \\
(575) \\
\end{array}$ & $\begin{array}{l}575 \\
(594) \\
\end{array}$ & $\begin{array}{l}179 \\
(181) \\
\end{array}$ & $\begin{array}{l}563 \\
(584) \\
\end{array}$ & $\begin{array}{l}191 \\
(192) \\
\end{array}$ \\
\hline & $\mathrm{PBE}+\mathrm{D} 3^{\mathrm{a}}$ & 419 & 139 & 607 & 338 & 74 & 422 & 172 & 419 & 179 & 359 & $\begin{array}{l}452 \\
(570) \\
\end{array}$ & $\begin{array}{l}567 \\
(584) \\
\end{array}$ & $\begin{array}{l}179 \\
(180) \\
\end{array}$ & $\begin{array}{l}564 \\
(582) \\
\end{array}$ & $\begin{array}{l}185 \\
(185) \\
\end{array}$ \\
\hline & Expt. ${ }^{a}$ & 437 & 143 & 631 & 356 & & & 181 & & & & & & & & \\
\hline & Expt. $^{b}$ & 430 & 138 & 625 & 351 & & & 181 & & 175 & & 590 & 402 & & 487 & \\
\hline & Expt. $^{\mathrm{c}}$ & & & & & & & & & & & 475 & & 188 & 475 & 188 \\
\hline & Calc. $^{d}$ & 445 & 143 & 640 & 363 & 64 & 450 & 181 & 443 & 187 & & $\begin{array}{l}485 \\
(610) \\
\end{array}$ & $\begin{array}{l}608 \\
(624) \\
\end{array}$ & $\begin{array}{l}191 \\
(192) \\
\end{array}$ & $\begin{array}{l}596 \\
(624) \\
\end{array}$ & $\begin{array}{l}191 \\
(192) \\
\end{array}$ \\
\hline \multirow[t]{9}{*}{$\begin{array}{l}\text { SiS } \\
\mathrm{e}_{2} \\
\end{array}$} & PBEsol+D3 ${ }^{\mathrm{a}}$ & 236 & 86 & 494 & 190 & 56 & 333 & 113 & 351 & 105 & 200 & $\begin{array}{l}369 \\
(449) \\
\end{array}$ & $\begin{array}{l}432 \\
(444) \\
\end{array}$ & $\begin{array}{l}118 \\
(119) \\
\end{array}$ & $\begin{array}{l}455 \\
(467) \\
\end{array}$ & $\begin{array}{l}102 \\
(103) \\
\end{array}$ \\
\hline & $\mathrm{PBE}+\mathrm{D} 3^{\mathrm{a}}$ & 235 & 87 & 491 & 194 & 56 & 340 & 109 & 331 & 115 & 201 & $\begin{array}{l}363 \\
(447) \\
\end{array}$ & $\begin{array}{l}448 \\
(458) \\
\end{array}$ & $\begin{array}{l}104 \\
(104) \\
\end{array}$ & $\begin{array}{l}437 \\
(448) \\
\end{array}$ & $\begin{array}{l}114 \\
(114) \\
\end{array}$ \\
\hline & Expt. $^{\text {a }}$ & 244 & 82 & 514 & 204 & & 350 & 113 & 350 & 113 & & & & & & \\
\hline & Expt. $^{b}$ & 248 & 82 & 512 & 204 & & 355 & 122 & 345 & 114 & & 492 & 397 & & 468 & \\
\hline & Expt. $^{e}$ & 242 & 68 & 515 & 216 & & 350 & 110 & 350 & 110 & & 490 & 390 & & 460 & \\
\hline & Expt. $^{\mathrm{e}}$ & 237 & 70 & 515 & 213 & & 357 & 125 & & 125 & & & 387 & & 470 & \\
\hline & Expt. $^{\mathrm{e}}$ & 236 & 70 & 521 & 202 & & 358 & 131 & & 131 & & & 380 & & 470 & \\
\hline & Expt. $^{\mathrm{f}}$ & 242 & 81 & 516 & 218 & 48 & 367 & 113 & & 113 & & & 399 & & 472 & \\
\hline & Expt. $^{\mathrm{g}}$ & 245 & 83 & 515 & 205 & 47 & 357 & 114 & 347 & 120 & & & & & & \\
\hline
\end{tabular}

${ }^{a}$ The present work by first-principles calculations or experiments.

${ }^{\mathrm{b}}$ Measurements by Tenhoveret al. [3][29]

${ }^{\mathrm{c}}$ Measurements by Begemannet al. [31]

${ }^{\mathrm{d}}$ Predictions using PBE0 as implemented in GRYSTAL06 by Zwijnenburget al. [7]

${ }^{\mathrm{e}}$ Measurements summarized by Arai et al. [4]

${ }^{\mathrm{f}}$ Measurements by Arai et al. [4]

${ }^{\mathrm{g}}$ Measurements by Griffiths et al. [13] 